\title{
Evaluation of novel peach cultivars in the European Union: the EUFRIN Peach and Apricot Working Group initiative
}

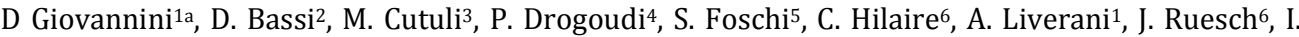 \\ Iglesias $^{7}$
}

${ }^{1}$ Council for Agricultural Research and Economics (CREA), Fruit Tree Research Unit, Forlì, Italy; 2Department of Agricultural and Environmental Sciences (DISAA), University of Milan, Milan, Italy

${ }^{3}$ Council for Agricultural Research and Economics (CREA), Fruit Tree Research Unit, Romea, Italy;

${ }^{4}$ Hellenic Agricultural Organization 'Demeter', Institute of Plant Breeding and Genetic Resources, Naoussa, Greece; ${ }^{5}$ Centro Ricerche ProduzioniVegetali (CRPV), Cesena, Italy;

${ }^{6}$ Centre technique interprofessionel des fruits et legumes (Ctifl), Bellegarde, France.

${ }^{7}$ Institut de_Recerca i Tecnologia Agroalimentàries(IRTA), Lleida, Spain

\section{Abstract}

Peach cultivars can undergo large performance variations when cultivated in different environmental conditions. As growers cannot afford the financial risk of choosing a cultivar unsuited to their specific conditions, information as comprehensive as possible on the marketed cultivars is useful and highly needed. Several organizations in the European Union (EU) are engaged in the performance assessment of the novel cultivars based on experimental trials. However, the exchange of information is overall poor, limiting the completeness of information on new releases that would derive from integrating the results obtained in various climatic and agronomical contexts. The Apricot and Peach working group established in 2014 within EUFRIN (European Fruit Research Institutes Network, www.eufrin.org) has recently embarked on a new initiative aiming to implement a collaborative varietal evaluation system in the EU countries. The first step was the establishment o_fa common list of descriptors_to assess the performance of peach cultivars in the testing trials. About 40 descriptors, related to different phenological traits as flowering or harvest_period, productivity, fruit appearance and internal quality, susceptibility to_physiological disorders and to some major diseases_in peach_were_selected. The protocols to measure and score each trait are being set up, as well as the selection of a common set of cultivars to include as references_in the various testing sites in order to homogenize_the evaluation. Implementation of this network will allow a real-time information exchange_on the new peach releases.

Keywords: descriptors, fruit quality, phenology,_P.persica L. (Batsch.), testing trials, agronomical performance, adaptability

\section{INTRODUCTION}

With a22.8 million ton production on a yearly global scale (FAOSTAT 2014), peach [Prunus persica (L.) Batsch] is a commercially important fruit tree crop. Hundreds of new peach and nectarine cultivars are released every year by_numerous private and public breeding programs worldwide (Della Strada and Fideghelli, 2008; Iglesias, in press). High yields, fruit attractiveness (eg. Large_fruit size, regular shape and extensive skin blush) and good taste are traditional goals in 
peach breeding, whereas the adaptability to a wide range of environments is rarely_taken into consideration as a criterion of selection (Reig et al., 2015). However, peach cultivars can undergo large performance variations when cultivated indifferent environmental conditions. For example, under the Ebro Valley conditions in Spain, only 10\% of the new tested cultivars provided a good agronomical performance and desirable fruit quality (Iglesias, in press). As growers cannot afford the financial risk of choosing a cultivar unsuited_to their specific conditions, information as comprehensive as possible on the marketed cultivars is needed.

Several organizations in the European Union (EU) are engaged in the assessment of varietal performance based on experimental trials. However, with few exceptions, the testing of new varieties is usually carried out individually; the experimental designs, methods and evaluation protocols used by various testers are often different; the dataand knowledge_sharing is poor and difficult. This state-of-art limits the completeness of information on the performance of newly introduced varieties that could instead result_from_the exchange of knowledge_and data_sets_issued in various climatic and agronomical contexts.

The Apricot and Peach working group (hereafter A\&P WG, Figure 1),_established in 2014 within EUFRIN (European Fruit Research Institutes Network, www.eufrin.org), has recently embarked on a new initiative aiming to implement a collaborative evaluation system of novel cultivars in the EU countries. The final goal_of this_initiative is to boost the harmonization of the varietal evaluation in the EU and to improve the dissemination and quality of information on the newly released cultivars. This paper reports the steps undertaken to develop this collaborative system and the results achieved so far.

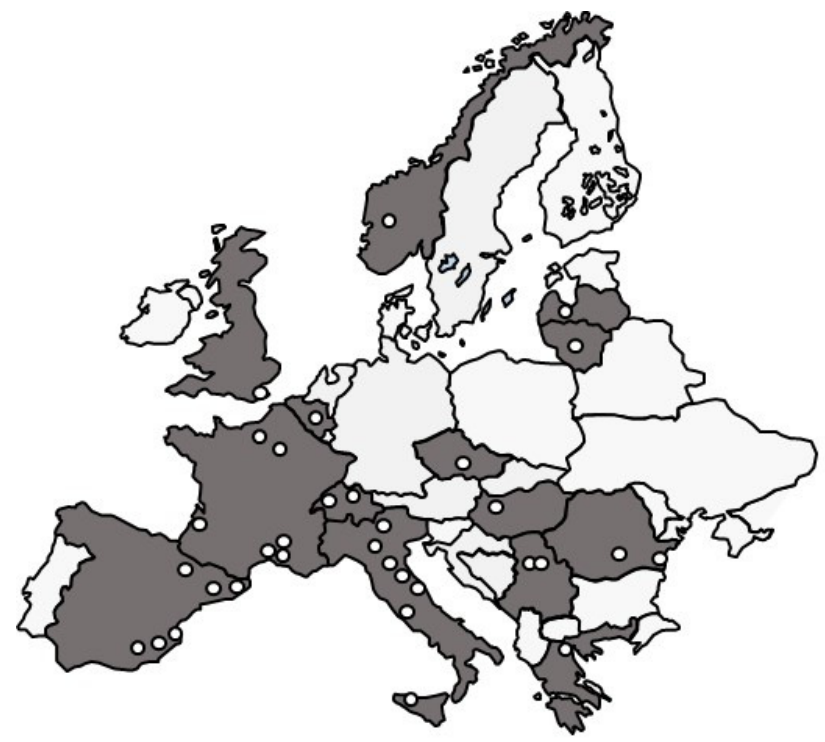

Figure 1. Location of the 33 EU Institutes participating to the EUFRIN A\&P WG 


\section{MATERIAL AND METHODS}

\section{Development of a standardized phenotyping _protocol}

The first step was to establish_a common phenotyping protocol with selected descriptors aiming_to harmonize the evaluation_of cultivar performance_across trials. Following some meetings, conference calls and mail exchanges organized since 2016, a panel of A\&P WG experts in peach variety testing from various EU institutes and countries agreed on a provisional list of the most effective traits for the assessment of a peach variety performance. The traits to include in the testing protocol, their definition and the methodology of measuring/assessing and scoring each trait were chosen following the available guidelines for peach characterization/evaluation, i.e. UPOV_(2010 and revision 2014)/CPVO (2015), ECPGR (Giovannini et al., 2013), and surveying the protocols in use for peach testing carried out at various research Institutes_participating in the EUFRIN network (CREA, Italy; Ctifl, France; IRTA, Spain). For each trait deemed important though not included in the existing guidelines, the panel agreed on developing a specific descriptor and a specific methodology for scoring it.

\section{List of Reference cultivars}

The panel of peach experts started the selection of a common set of reference cultivars to include in the testing trials. This aimed to facilitate the correct scoring of new cultivars for each trait and the harmonization of the datasets issued from various testing sites. The followingkey criteria for choosing the reference cultivars were agreed:

- Well-known, with proven good constant_yield and fruit quality performance (pack-out_i.e. the percentage of the marketable yield) in the relevant peach growing areas;

- Representing the most important commercial peach fruit categories: yellow- and whitefleshed peach and nectarines; early, medium and late ripening period; sweet and equilibrate/acid taste; round and flat shape;

- Diverse genetic background.

\section{RESULTS AND DISCUSSION}

The provisional list of peach descriptors (herein after List) drafted so far includes 43 descriptors related to flower and harvest phenology, tree fertility and vigor, yield and yield efficiency, fruit external and internal quality, susceptibility to pre-harvest and post-harvest disorders and to major peach diseases (Table 1).

Most (78\%) of the traits in the List are regularly assessed/measured in testing trials, as they are universally considered effective to describe the agronomic value and fruit quality of a cultivar. However_the protocols, methods and scales used by the testers are often diverse. On the other hand, the use_of a common procedure for phenotyping each trait is the pre-requisite for the comparability of datasets issued from different experiments and the production of Variety Description Sheets taking into account information from a range of different agro-ecological environments. For this reason, a phenotyping protocol widely shared within the WG, based on easy-to-use methods, effective in assessing the cultivar performance and enriched with explicative drawings and pictures, is highly needed.

The List includes some traits that are not routinely measured in testing trials, but that are important in specific environments. This is the case of the chilling requirement, which is a crucial information in growing sites featured with climatic conditions which normally prevent the tree from receiving adequate chilling to overcome dormancy (Weinberger, 1950). In these environments, that can be found in Southern Spain, Italy and Greece, cultivars featured with 
medium-to-high chilling requirement tend to perform very poorly, showing erratic flowering and fruit set, low fruit quality and poor yield (Lesley and Winslow, 1961; Wert et al., 2007; Nava et al., 2009; Ghrab et al., 2014). Similarly, in the high chilling areas where frost occurrence at the end of winter is not so infrequent (Ebro Valley, Spain; Roussillon, France or Emilia-Romagna, Italy), cultivars with low chilling requirement tend to bloom too early and to be at a risk of poor yields.

Table 1. List of selected traits for the standardized phenotyping protocol for peach and relative priority.

\begin{tabular}{|c|c|c|c|}
\hline Category & \# & Trait & Priority \\
\hline \multirow{8}{*}{ 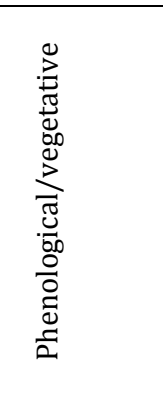 } & 1 & Beginning of leaf bud burst & 2 \\
\hline & 2 & Beginning of flowering & 1 \\
\hline & 3 & Full flowering & 1 \\
\hline & 4 & End of flowering & 2 \\
\hline & 5 & Beginning of ripening & 1 \\
\hline & 6 & Additional picking dates & 2 \\
\hline & 7 & Chilling requirement & 2 \\
\hline & 8 & Tree vigour & 1 \\
\hline \multirow{5}{*}{$\begin{array}{l}\stackrel{己}{D} \\
.0 \\
0 \\
0 \\
0 \\
0\end{array}$} & 9 & Intensity of blooming & 1 \\
\hline & 10 & Fruit set & 1 \\
\hline & 11 & Yield per tree & 1 \\
\hline & 12 & Fruit weight & 1 \\
\hline & 13 & Fruit size distribution & 2 \\
\hline \multirow{9}{*}{ 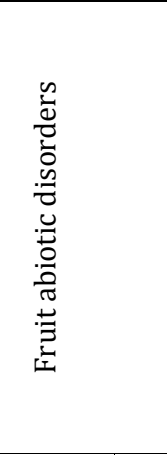 } & 14 & Fruit split-pit (included non visible) & 1 \\
\hline & 15 & Skin cracking (mainly in nectarines) & 1 \\
\hline & 16 & Pistilar cavity closing & $1^{*}$ \\
\hline & 17 & Fruit doubles & 2 \\
\hline & 18 & Skin russetting (in nectarines) & 1 \\
\hline & 19 & Skin speckling (in nectarines) & 1 \\
\hline & 20 & Corky spot & 2 \\
\hline & 21 & Skin bronzing & 2 \\
\hline & 22 & Skin wrinkling & 2 \\
\hline \multirow{5}{*}{ 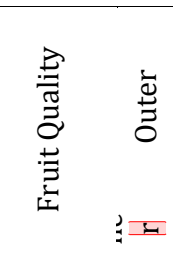 } & 23 & Fruit shape (lateral view) & 1 \\
\hline & 24 & Fruit shape (transversal view) & 1 \\
\hline & 25 & Fruit blush \% & 1 \\
\hline & 26 & Red over colour pattern & 2 \\
\hline & 27 & Sugar content & 1 \\
\hline
\end{tabular}




\begin{tabular}{|c|c|c|c|}
\hline & 28 & Acidity content & 1 \\
\hline & 29 & Fruit Taste & 1 \\
\hline & 30 & Flesh firmness & 2 \\
\hline & 31 & Flesh texture & 1 \\
\hline \multirow{3}{*}{ 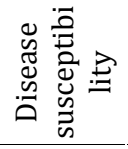 } & 32 & Brown rot & 2 \\
\hline & 33 & Leaf curl & 2 \\
\hline & 34 & Powdery mildew & 2 \\
\hline \multirow{3}{*}{ 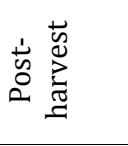 } & 35 & Storability & 2 \\
\hline & 36 & Brown rot susceptibility & 1 \\
\hline & 37 & Fruit skin inking & 2 \\
\hline \multirow{5}{*}{ 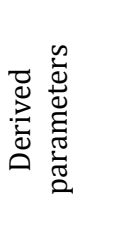 } & 38 & Lenght of blooming period & 2 \\
\hline & 39 & Pack-out & 2 \\
\hline & 40 & Yield efficiency & 1 \\
\hline & 41 & Fruit size uniformity & 2 \\
\hline & 42 & Ripening uniformity & 2 \\
\hline
\end{tabular}

* For flat peaches

The 'Fruit disorders' category_in Table 1_includes descriptors for a number of traits that are gaining importance in the evaluation of novel peach and nectarine cultivars because, beyond a certain level, negatively impact on the cultivar pack-out. This is the case of the skin speckling (or lenticellosis), particularly serious in susceptible nectarines that may develop widespread skin blemish in the stylar end and cheek zones. Speckling has been positively associated with the soluble solids content in the flesh and each speckle appears to originated at a lenticellenticels (Topp and Sherman, 2000). Extensive speckling in the skin is more frequent in continental climatic conditions characterized by high temperatures and low relative humidity in spring-summer period (Iglesias, in press). The same category includes also fruit malformations such as 'fruit doubling', a disorder boosted by severe water stress (eg. very hot and dry summers) during flower bud differentiation, affecting up to $50 \%$ of the following-year production depending on the stress intensity and on the genotype (Handley and Johnson, 2000). For each disorder, specific evaluation protocols_are under development if not included in the available Guidelines.

Finally, the panel decided to assign a priority label to those traits that should be evaluated by all variety testers willing to join the common evaluation system, and to leave the other ones at the testers' discretion._About $50 \%$ of the traits in the List were prioritized (Table 1).

The feasibility and the robustness of the developed protocols will be tested and validated, if necessary, by organizing inter-calibration procedures aimed to reveal discrepancies in the evaluation scoring and rankings from the various variety testers. Agronomic (eg. rootstock and planting system), climate (eg. air temperature, rain) and soil (eg. texture, pH) variables will be provided by variety testers to explain better each testing site. Once finalized, the Guidelines for Peach Testing will be uploaded on the EUFRIN website and publicly available. 
Table 2. Provisional list of cultivars chosen as references, their fruit type, flesh color and acid/sugar balance, and_harvest period.

\begin{tabular}{|c|c|c|c|c|c|}
\hline$\#$ & Cultivar & $\begin{array}{l}\text { Fruit } \\
\text { type }\end{array}$ & $\begin{array}{l}\text { Flesh } \\
\text { colour }\end{array}$ & $\begin{array}{l}\text { Acid/sugar } \\
\text { balance* }\end{array}$ & $\begin{array}{l}\text { Harvest } \\
\text { period }\end{array}$ \\
\hline 1 & Carlacov & Peach & Yellow & Sweet & Early \\
\hline 2 & Crimson Lady & Peach & Yellow & Equilibrate & Early \\
\hline 3 & Sweet Dream & Peach & Yellow & Sweet & Medium \\
\hline 4 & Elegant Lady ${ }^{\circledR}($ Merdame $)$ & Peach & Yellow & Equilibrate & Medium \\
\hline 5 & O’ Henry® & Peach & Yellow & Equilibrate & Late \\
\hline 6 & Patty ${ }^{\circledR}$ (Zaisito) & Peach & White & Acid & Early \\
\hline 7 & Tonicsweet $®$ Sweetregal cov & Peach & White & Sweet & Medium \\
\hline 8 & Gladys ${ }^{\circledR}$ & Peach & White & Acid & Late \\
\hline 9 & Samanthacov & Flat Peach & White & Sweet & Early \\
\hline 10 & Sweet Cap $®$ (Maillarflat) & Flat Peach & White & Sweet & Medium \\
\hline 11 & Regalcake ${ }^{\circledR}$ Flatstar cov & Flat Peach & White & Sweet & Late \\
\hline 12 & Ambra & Nectarine & Yellow & Acid & Early \\
\hline 13 & BigTop $®$ (Zaitabo) & Nectarine & Yellow & Sweet & Medium \\
\hline 14 & Venus $®$ & Nectarine & Yellow & Acid & Medium \\
\hline 15 & Nectapom $®$ Nectadiva cov & Nectarine & Yellow & Sweet & Late \\
\hline 16 & Caldesi2000 (Superqueen) & Nectarine & White & Acid & Early \\
\hline 17 & Emeraude $®$ & Nectarine & White & Sweet & Medium \\
\hline 18 & Nectasweet ${ }^{\circledR}$ Nectarperf cov & Nectarine & White & Sweet & Late \\
\hline 19 & Romea & Canning peach & Yellow & Equilibrate & Early \\
\hline 20 & Catherina ${ }^{\circledR}$ & Canning peach & Yellow & Equilibrate & Medium \\
\hline 21 & Baby Gold 8 & Canning peach & Yellow & Equilibrate & Late \\
\hline
\end{tabular}

$\left({ }^{*}\right)$ based on Iglesias and Echeverria (2009)

Regarding the choice of references, the panel of experts drafted a list of 21cultivars complying the initially stated criteria. White- and yellow-fleshed peaches and nectarines, of early, medium and late harvest season and various genetic background are represented quite fairly (Table 2). Similarly, the sweet-taste cultivars (featured by a flesh acidity 2-4 fold lower than standard phenotypes, Bassi and Monet, 2008) are well represented. This choice reflects i) the increasing number of low-acid cultivars released from the relevant breeding programs worldwide and ii) the increasing consumer liking towards this product (Bonany et al., 2014).

\section{CONCLUSIONS}

The initiative of the A\&P WG established in EUFRIN is the first one, at the EU level, aiming at harmonizing varietal evaluation system in peach. A similar initiative was undertaken about 20 
years ago by the EUFRIN Apple and Pear WG and has produced a unified list of agro-pomological descriptors for apple including more than 30 descriptors (www.eufrin.org). Moreover, in order to facilitate the accessibility to the new apple and pear varieties protected by Plant Variety Rights (PVR) for a public evaluation, the Apple and Pear WG has also drawn up the "Testing agreement for fruit plant material' (Guerra, 2007; www.eufrin.org)._Such_testing agreement is a standardized contract between testers and breeders (or exclusive rights holders of varieties) setting up the rules for the acquisition and the evaluation of the genetic material of interest and the publication of the information acquired by testers. A similar agreement will_be developed also for accessing the newly released peach and nectarine cultivars for testing purposes.

The establishment of a network of testing trials in the EU will improve the dissemination and quality of information on the recently released varieties and facilitate growers in the selection and in the best use of those cultivars evaluated as productive, stable and of excellent quality in their specific environment, having the final scope to increase the competitiveness of EU peach industry. Moreover, the harmonized multi-site datasets opportunely elaborated will allow Genotype $\mathrm{x}$ Environment interaction assessment for important traits, helping in the identification of traits less (or more)_impacted by the environment. This knowledge might help breeders in obtaining cultivars more adapted to different EU growing areas. Finally, this activity might contribute to the evolution from a DUS- to a VCU-based (value for cultivation or use) evaluation of new varieties also for the fruit industry. Today, DUS is the only legal requirement for completing positively the application process for the protection of a new fruit variety. However, given the numerous yearly releases, it seems increasingly important to confirm whether a candidate variety has satisfactory value for cultivation or use, and this can be acknowledged only introducing VCUS as a part of the application process.

\section{Literature Cited}

Bassi, D., and R. Monet (2008). Botany and taxonomy. In The Peach. Botany, production and uses. D.R.Layne and D.Bassi eds., 1-36 pp.http://dx.doi.org/10.1079/9781845933869.0001

Bonany, J., Carbo, J., Echeverria, G., Hilaire, C., Cottet, V., Iglesias, I., Jesionkowska, K., Konopacka, D., Kruczynska, D., Martinelli, A., Predieri S., Medoro, C., and Liverani, A. (2014). Eating quality and European consumer acceptance of different peach (Prunus persica (L.) Batsch) varieties. Journal of Food, Agriculture and Environment, 12(1):67-72.

CPVO.(2015). Protocol for tests on distinctness, uniformity and stability, Prunus persica (L.) Batsch. Peach/Nectarine. http://cpvo.europa.eu/sites/default/files/documents/TP/adopted/CPVO-TP_PRUNUS PERSICA 053-2 Rev.pdf

Della Strada, G., and Fideghelli, C. eds. (2010). The fruit varieties released in the world from 1980 through 2008 . Rome, Italy.

European Fruit Research Institutes Network. www.eufrin.org

FAOSTAT. 2014. http://www.fao.org/faostat

Frett, T., Gasic, K., Clark, J., and Byrne D. (2012). Standardized phenotyping for fruit quality in peach (Prunus persica (L.) Batsch). Journal of the American Society for Horticultural Science 66(4):214-219.

Giovannini, D., Liverani, A., Bassi, D., and Lateur, M. (2013). ECPGR Priority Descriptors for Peach[Prunus persica (L.) Batsch].

(http://www.ecpgr.cgiar.org/fileadmin/templates/ecpgr.org/upload/NW and WG UPLOADS/Prunus/Peach descriptor S DRAFT 13008 13.pdf ).

Ghrab, M., Mimoun, M.B., Masmoudi, M.M., and Mechlia, N.B. (2014). Chilling trends in a warm production area and their impact on flowering and fruiting of peach trees. Scientia Horticulturae178, 87-94.

Guerra, W. (2007). Accordo internazionale per la valutazione pubblica delle nuove varietà brevettate. Rivista di Frutticoltura, 12:32-34.

Handley, D.F. and. Johnson, R.S. (2000). Late summer irrigation of waterstressed peach trees reduces fruit doubles and deep sutures. HortScience 35:771.

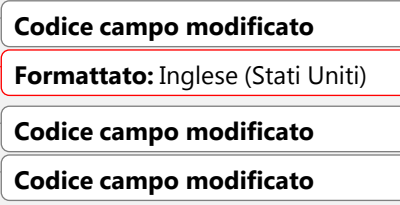

Formattato: Inglese (Stati Uniti)

Codice campo modificato

Codice campo modificato

Formattato: Italiano (Italia) 
Iglesias, I., and Echeverria G.. (2009). Differential effect of cultivar and harvest date on nectarine colour, quality and consumer acceptance. Scientia Horticulturae 120: 41-50.

Iglesias, I. in press. Overview of peach industry in the European Union: from production to consumption. IX International Peach Symposium, Bucharest July 2-7, 2017. Acta Horticulturae.

Lesley, J.W., and Winslow M.M. (1961).Behavior of short-chilling Peach Varieties in Southern California after warm winter of 1960-1961. California Agriculture, 8:8-10.

Nava, G.A., Dalmago, G.A., Bergamaschi, H., Paniz, R., Santos, R.P., Marodin, G.A.B. (2009). Effect of high temperatures in the pre-blooming and blooming periods on ovule formation, pollen grains and yield of 'Granada' peach. Scientia Horticulturae 122: 37-44.

Reig, G., Alegre, S., Gatius, F., Iglesias, I. (2015). Adaptability of peach cultivars [Prunus persica (L.) Batsch] to the climatic conditions of the Ebro Valley, with special focus on fruit quality. Scientia Horticulturae 190, 149-160.

Topp, B.L., and Sherman, W. B. (2000). Nectarine skin speckling is associated with flesh soluble solids content. Journal of the American Pomological Society, 54(4), 177-182.

Weinberger, J.H. (1950). Chilling requirements of peach varieties. In Proceedings of American Society for Horticultural Science, 56:122-128.

Wert, T.W., Williamson, J.G., Chaparro J.X., Miller E.P. (2007). The Influence of Climate on Fruit Shape of Four Low-chill Peach Cultivars. HortSci. 42(7):1589-1591. 2007.

UPOV. (2010). Guidelines for the conduct of tests for distinctness, uniformity and stability. Peach. TG/53/7. International Union for the Protection of New Varieties of Plants, Geneva,http://www.upov.int/edocs/tgdocs/en/tg053.pdf and partial revision

UPOV. (2014). Partial revision of the Test Guidelines for Peach (document TG/53/7). http://upov.int/edocs/mdocs/upov/en/tc 50/tc 50 33.pdf

Codice campo modificato 